\title{
Pupillary response as a general measure of activation'
}

JUM C. NUNMALLY, PAUL D. KNOTT, ALBERT DUCHNOWSKI, AND RONALD PARKER ${ }^{2}$

VANDERBILT UNIVERSITY

Pupil size was measured while 30 male college students undertook five tasks respectively concerming (a) muscle tension induced by the lifting of weights, (b) fear induced by threat of a gunshot, $(c)$ intense stimulation induced by loud pure tones, (d) heightened attention from viewing novel pictures, and (e) pleasantness and unpleasantness in reaction to pictures that differed in terms of their affect-inducing characteristics. Highly regular relationships were found between pupil size and degree of muscle strain and between pupil size and the temporal ordering of events during threat of a gunshot. Significant effects on pupil size also were found for the other three types of stimulation.

From a variety of research traditions have come suggestions that pupillary response is a universal accompaniment of all types of activation, in a very broad sense of the word, including activation related to emotional states, physical tension, heightened attention, "mental effort" in problem solving, and reactions to pleasant and unpleasant stimuli. That contention was voiced over 45 years ago by a person who spent a lifetime investigating the intricacies of pupillary response (Lowenstein, 1920). He stated that dilation of the pupil occurs "with every increase of attention by intellectual processes of every kind, with the beginning of the volitional impulses, or during the course of emotions." More recently similar strong contentions have been voiced by Hess (1965) and by Sokolov (1963) regarding the participation of pupillary response in many forms of activation.

The hypothesis that pupillary response is a general indicator of activation is supported by a wealth of anecdotal evidence, numerous incidental observations in studies of other response systems, and by some controlled experiments (evidence summarized by Hess, 1965; and by Loewenfeld, 1958). The importance of that contention, if correct, lies partly in an increased understanding of the pupillary response, but, to a much greater extent, the importance lies in the potential usefulness of pupillary response as a measure of activation in numerous types of experiments. Traditionally, measures of activation have been in relation to GSR, heart rate, vaso constriction, and other components of autonomic activity-all of which have their problems as measures of activation. A new measure of activation will be welcomed if it has fewer methodological problems than traditional methods, and if, in comparison to other methods, it relates as reliably or more reliably to a variety of forms of activation.

The purpose of the present experiment was to partially test the sensitivity of pupillary response to five types of stimulation: (a) muscle tension induced by the lifting of weights, (b) fear induced by threat of a gunshot, (c) intense stimulation induced by loud pure tones, (d) heightened attention (orienting responses) from viewing novel pictures, and (e) pleasantness and unpleasantness in reaction to pictures that differed in terms of their affect-inducing characteristics. These five types of stimulation were employed because (a) they represent a wide spectrum of things that one or another person has referred to as "activating" and (b) at least superficially, they appear to concern very different response systems.

\section{Subjects}

\section{METHOD}

The Ss were 30 male undergraduates enrolled in introductory psychology courses at Vanderbilt University. They served as Ss as part of a course requirement. The Es were two male graduate students.

\section{Apparaitus}

The apparatus used for photographing the pupil was essentially the same as that discussed and illustrated by Hess (1965). This apparatus was a box $11 \times 14 \times 24$ in. into which $\mathrm{S}$ peered by resting his head against a goggle-like opening at the front. The rear contained a screen $11 \times 11-1 / 2$ in. onto which slides were projected by a Bell and Howell slide projector $3 \mathrm{ft}$. away from the screen. A timer connected to the projector presented each slide for $10 \mathrm{sec}$. A Bolex $16 \mathrm{H} 16 \mathrm{~mm}$ movie camera with a $100 \mathrm{~mm}$ lens was mounted on the right side of the box with the lens extended through an opening in the box focused on a small mirror mounted on the inside. The mirror reflected the image of S's left eye into the lens. The camera lens and mirror were below S's eye level, thus permitting him an unobstructed view of the screen. The pupil was photographed using Kodak high speed infrared film. An auxiliary motor drove the camera at 2 frames per sec. A 25-W red light bulb provided the photographic light source and was on during the entire presentation of the stimuli. The bulb was encased in a reflector aimed at the middle of the goggle-like opening. The reflector base was attached to the floor of the box approximately $10 \mathrm{in}$. from the face of the box.

The technique for making the photographic slides of the visual stimuli was the same as that described by Woodmansee (1965). Neutral filters of varying degrees of density were used to reduce contrast, 
Table 1. Mean Readings in Foot-Lamberts for Stimuli Used in First Three Tasks

\begin{tabular}{|c|c|c|}
\hline Stimuli & $\begin{array}{l}\text { Test Slide } \\
\text { Readings } \\
\text { (Ft. L.) }\end{array}$ & $\begin{array}{c}\text { Confrol Slide } \\
\text { Readings } \\
\text { (Ft. L.) }\end{array}$ \\
\hline \multicolumn{3}{|c|}{$\begin{array}{l}\text { Novel vs. Non-novel Pictures } \\
\text { Set A: }\end{array}$} \\
\hline Novel & 42.80 & 44.55 \\
\hline Non-novel & 45.20 & 43.60 \\
\hline \multicolumn{3}{|l|}{ Set B: } \\
\hline Novel & 44.80 & 45.20 \\
\hline Non-novel & 45.60 & 44.80 \\
\hline \multicolumn{3}{|l|}{ Semi-nude Female } \\
\hline Test Slide No. 1 & 25.20 & 14.80 \\
\hline Test Slide No. 2 & 23.40 & 15.20 \\
\hline Test Slide No. 3 & 24.20 & 15.00 \\
\hline Test-Slide No. 4 & 24.40 & 15.00 \\
\hline \multicolumn{3}{|c|}{ Other Affect-related Stimuli } \\
\hline & 16.25 & 5.53 \\
\hline \multirow[t]{2}{*}{ Positive } & 16.60 & 5.42 \\
\hline & 16.95 & 5.25 \\
\hline \multirow{3}{*}{ Neutral } & 15.50 & 5.80 \\
\hline & 15.80 & 6.08 \\
\hline & 16.10 & 6.12 \\
\hline \multirow{3}{*}{ Negative } & 15.60 & 5.50 \\
\hline & 16.00 & 5.65 \\
\hline & 16.40 & 5.65 \\
\hline
\end{tabular}

but the detalls of meaningful pictures were kept intact.

A Spectra spotphotometer was used to determine the luminance levels of the visual stimuli. Luminance measures were made at five points on each picture: in the center and approximately 1 in. inward from each corner toward the center. These luminance measures were made to partially insure that the photographic process had adequately matched visual stimuli, which would reduce the possibility that differences in pupillary response to different types of visual displays would be due to artifacts relating to the amount and distribution of luminance.

Table 1 shows the mean luminance of the five measures on each test and control slide used in the tasks that required visual displays. The ranges and standard deviation about these means were very small, i.e., the widest range about any mean on any slide was less than $7 \mathrm{ft}$. $-\mathrm{L}$.

\section{General Procedure}

When $S$ came into the experimental room, he was given a 3-min. period of adaptation to the level of illumination in the room. The only light source in the experimental room was a $50-W$ red light bulb placed approximately $10 \mathrm{ft}$. from the apparatus, thereby making the overall illumination in the room approximately equal to that inside the apparatus. During the adaptation period, $S$ was given the following instructions by one of the Es:

In this experiment you will be looking at some pictures and performing some simple tasks while this camera will be photographing your eyes.
It is important that you do not move your head once the camera is set; therefore, try to get in a comfortable position. You will be given a rest after each of several short sessions. This is not a learning experiment, and you will not be asked to recall any of the material. Do you have any questions?

$\mathrm{E}$ answered questions about procedures but requested that any questions about the purposes of the experiment be delayed until the experimental tasks were completed.

\section{Procedure and Stimuli for the Six Tasks}

All Ss participated in the same six tasks in the same order: (a) novel versus non-novel pictures, (b) pictures of a semi-nude female, (c) other affectrelated pictures, (d) levels of sound intensity, (e) lifted weights, and (f) threat of a gunshot. Between each of the six tasks, $S$ was given a 3 min. rest period, during which time he was free to remove his head from the apparatus and look around the room.

In the first three tasks a control slide was presented before each test slide. The control slide consisted of the numbers $1,2,3$, and 4 in the corners and the number 5 in the center of the slide. The numbers were black on a light gray background. In each task at least two control slides were presented before the first test stimulus in order to give $S$ additional time in which to adjust to the level of illumination inside the box. Each test slide and each control slide were presented for $10 \mathrm{sec}$.

Novel Pictures. These stimuli were two sets of achromatic outline drawings similar to those depicted by Berlyne (1966). In the first set, the non-novel picture consisted of simple line drawings of a flower and airplane. The novel picture consisted of the front of the airplane mixed with the stem of the flower and the bloom of the flower mixed with the rear of the airplane. In the second set, the non-novel picture was a line drawing of a panther, and the novel stimulus was the body of a panther with the head of an elephant.

A control slide preceded each of the four test slides, and $S$ viewed each slide for $10 \mathrm{sec}$. Among the test slides, the non-novel pictures preceded the novel pictures.

Semi-nude female. Four chromatic test slides (each with a prior achromatic control slide) were presented to $S$. The first test slide was a picture of a pretty girl, fully clothed. The second test slide showed the girl lifting her sweater over her head, thereby revealing her brassiere. The third test slide showed the girl lying on her back on a bed, dressed in bikinitype underwear. The fourth test slide showed her again on the bed, this time with her bikini top apparently removed.

Because of the relatively high level of complexity and the use of color in the test slides (and the problems that ensue-see Loewenfeld, in press; and Woodmansee, 
1966), it was decided to establish a slight bias against the test slides. Consequently the control slides were made slightly darker than the test slides, thereby raising the probability that $\mathrm{Ss}$ would dilate to control slides rather than to test slides (see Table 1).

Other affect-related pictures. The test slides in this series were nine chromatic pictures varying in level of affect from very unpleasant to very pleasant. These pictures were rated previously on a 9-point scale of pleasantness by 62 undergraduate male students, none of whom participated in the study of pupillary response. The mean ratings on the three positive pictures were $8.1,8.3$, and 8.5 ; on the neutral pictures, 5.2, 5.3, and 5.6; and on the three negative pictures, $1.4,1.5$, and 1.7 .

Again, each test slide was preceded by a control slide, and all slides were viewed for 10 sec. One random order of presentation was employed with all Ss. The order and content of each test slide was as follows: (1) neutral, a middle-aged woman sitting in a flower garden; (2) neutral, a middle-aged man sitting on a bench in a park; (3) positive, the face of a pretty female fashion model; (4) negative, a man with a disfigured face due to a cancerous growth; (5) negative, another man with a cancerous growth on his face; (6) neutral, the face of a plain girl; (7) positive, the face of a pretty female fashion model; (8) negative, a woman with a cancerous growth on her neck and upper chest; (9) positive, another face of a pretty female fashion model. As in the previous task, control slides were darker than test slides (see Table 1).

Auditory stimuli. Before beginning this task, the following instructions were given to $\mathrm{S}$ :

During this next session, you will be listening to some tones through the earphones. There will not be any pictures on the screen during this series, so just look at the center of the screen. Adjust the earphones so that they fit comfortably and then look into the apparatus. Be sure to try to look at the center of the screen. We will begin in $1 \mathrm{~min}$.

The earphones were connected to an audio-generator delivering a tone of $64.2 \mathrm{~dB}$ at $2000 \mathrm{cps} . \mathrm{S}$ heard this tone for $60 \mathrm{sec}$. before the first $10-\mathrm{sec}$. test period began (which was also $64.2 \mathrm{~dB}$ at $2000 \mathrm{cps}$ ). The audio-generator used was a Hewlett-Packard model which produced a sine wave pure tone. The different $\mathrm{dB}$ levels were checked at the headset by means of an Allison direct reading sound level meter (Model 300). Seven different tones, varying in intensity but at the same frequency of $2000 \mathrm{cps}$, were serially presented to $\mathrm{S}$ for $10 \mathrm{sec}$. each. The intensity levels in their order of presentation were: $64.2 \mathrm{~dB}, 74.2 \mathrm{~dB}, 84.2$ $\mathrm{dB}, 84.2 \mathrm{~dB}, 94.2 \mathrm{~dB}, 84.2 \mathrm{~dB}, 74.2 \mathrm{~dB}$, and $64.2 \mathrm{~dB}$. The screen of the apparatus was lit from behind by a $25-\mathrm{W}$ bulb, this being done to provide a homogeneous visual field. The range of brightness on the screen was 13-16 ft.-L, with a mean reading of $14.4 \mathrm{ft} .-\mathrm{L}$.

Muscle tension. During the 3-min. rest period after the task concerning sound levels, the two Es demonstrated the next task for $S$. One $E$ sat in the chair peering into the apparatus while the other $\mathrm{E}$ put various amounts of iron weights into a plastic bucket, which the first $E$ lifted to a height of $1 \mathrm{ft}$. The weight was lifted to a height where it touched a crossbar of the chair, which was $1 \mathrm{ft}$. from the floor. Then $\mathrm{S}$ sat in the chair and became adjusted to lifting the bucket, both while it was empty and while it contained weights. The following instructions were then given to S:

In this next session, we will give you various amounts of weight to lift. This is not a test of strength, and the heaviest weight will not be overly taxing. We will begin with a $10-\mathrm{sec}$. rest period. Then I will say "up," at which time you will lift the bucket with your right hand and hold it for $10 \mathrm{sec}$. Then I will say "down" signalling a $10-\mathrm{sec}$. rest period. We will repeat this sequence several times. There will not be any pictures on the screen this time, so just look at the center of the screen.

The screen was illuminated in the same way as in the task concerning sound levels. $S$ was given a 10-sec. rest period after the camera was started, and then $E$ said "up," at which time $S$ lifted $10 \mathrm{lb}$. A rest period followed when $\mathrm{E}$ said "down." Then $\mathrm{S}$ lifted $20 \mathrm{lb}$., $30 \mathrm{lb} ., 20 \mathrm{lb}$., and $10 \mathrm{lb}$, for $10 \mathrm{sec}$. each, with a 10-sec. rest between each. A rest period was also recorded after the last $10 \mathrm{lb}$. weight had been lifted.

Anticipation of gunshot. While one E loaded blank cartridges into a .22 caliber pistol in view of $\mathrm{S}$, the other $\mathrm{E}$ gave the following instructions to $\mathrm{S}$ :

During this session you will see the numbers $1,2,3,4$, and 5 on the screen in that order. Each number will appear for $10 \mathrm{sec}$. At some time while the number 3 is on the screen this gun may fire. It may fire when the number 3 is on, or it may not. But let me assure you that we will fire the gun only while the number 3 is on and not during the exposure of any other number. As you can imagine, the noise will be quite loud in this small room. This is what it will sound like. ( $\mathrm{E}$ pointed the gun toward the ceiling away from $S$ and fired.) Remember, the gun will only fire when 3 is on, and the entire sequence will be presented twice without any break in between. In either series if the number 4 appears and the gun has not been fired, then you will know that in that series the gun is not to be fired. Try to keep your head still in the apparatus when the gun is fired so that you do not move your eye out of the camera range.

An additional $2-\mathrm{min}$. rest was given to $S$ (so that 
he could "settle down" from the firing of the gun), and then the series was begun. Actually the gun was never fired for any $S$ during either sequence. Each $\mathrm{S}$ was told at the end that he was in the "lucky" group that did not experience the firing of the gun.

The range of mean luminance levels among both the control and the number slides was $3-7 \mathrm{ft} .-\mathrm{L}$, and the grand mean was $5.13 \mathrm{ft} .-\mathrm{L}$.

When Ss were dismissed, they were asked not to reveal to any of their classmates the materials used in the study.

\section{RESULTS}

The actual photographed size of S's pupil was magnified approximately 17.5 times and projected onto a screen. Pupil diameter was then measured with a meter stick by individuals who had no knowledge of the experimental tasks corresponding to the frames of the film. This magnified pupil size comprises the data in all analyses reported here. Because pupil size on the film is not the same as the actual pupil size, and because of the magnification of pupil size on the film, the raw measures reported here are in terms of an arbitrary, constant multiple of actual pupil diameter.

Each stimulus was presented for $10 \mathrm{sec}$. at 2 frames of film per sec. The pupil size was recorded for each frame, and then the mean pupil size over the 20 frames per stimulus was obtained for each $S$ on each stimulus.

Although the same 30 Ss were used in all tasks, losses of data due to poor photographic records in some cases resulted in Ns ranging from 25 to 30 for the different tasks. The results for the various kinds of tasks will be discussed separately.

\section{Novelty.}

Since there were two comparisons of novel and non-novel pictures, a 2 by 2 analysis of variance was computed $(\mathrm{N}=26)$. The difference between novel and non-novel pictures is significant (means of 66.87 $\mathrm{mm}$ and $64.80 \mathrm{~mm}$ respectively; $F=20.08, \mathrm{df}=1 / 25$, $p<.001)$. The difference between the first and second set of pictures also is significant (means of $67.69 \mathrm{~mm}$ and $63.97 \mathrm{~mm}$ respectively; $F=14.29, \mathrm{df}=1 / 25, \mathrm{p}<$ $.001)$. The interaction between the two facets of the design is significant $(F=7.03, \mathrm{df}=1 / 25, p<.02)$.

The significant interaction is due to the fact that the difference between novel and non-novel pictures is larger in the first set than in the second set. The means for the novel and non-novel pictures in the first set are $69.39 \mathrm{~mm}$ and $66.00 \mathrm{~mm}$ respectively, and the respective means in the second set are $64.25 \mathrm{~mm}$ and $63.60 \mathrm{~mm}$. The former difference is significant $(t=5.63, d f=25, p<.001)$, but the latter difference is not significant.

\section{Affect-related picfures: Semi-nude female.}

The mean pupil size $(\mathrm{N}=26)$ on the first test stimulus (a slide of a pretty girl fully clothed) was 68.62 $\mathrm{mm}$. The next three test stimuli were slides of the same girl in various states of undress. The means on these latter three stimuli were, in order: $74.26 \mathrm{~mm}$, $73.35 \mathrm{~mm}$, and $73.74 \mathrm{~mm}$. An analysis of variance comparing these four means showed significance $(F=19.02$, df $=3 / 75, p<.001)$. Duncan's test for multiple comparisons indicated that the latter three means did not differ significantly from each other, but all three of them differed significantly from the mean on the first test slide ( $p<.001$ in each case).

The data in this series also were analyzed by comparing pupil size during test slides with that during the four prior control slides (one control slide having appeared before each test slide). With no difference between test and control slides, the expected grand mean would be 0 . The obtained grand mean, in terms of differences between test and control slides, was 1.65 , which showed significance when compared against the expected mean of $0: t=5.55, d f=25, p<.001$.

\section{Other affect-related pictures}

The mean pupil size for all Ss $(N=30)$ on the three positive pictures was $70.44 \mathrm{~mm}$, on the three neutral pictures, $69.35 \mathrm{~mm}$, and on the three negative stimuli, $69.08 \mathrm{~mm}$. An analysis of variance comparing these three means showed significance: $F=5.18$, $\mathrm{df}=$ $2 / 58, p<.009$. Duncan's test indicated that the mean for the positive stimuli was significantly larger than the neutral mean $(p<.05)$, and the negative mean as well $(p<.01)$. The means for the neutral and negative stimuli did not differ significantly.

\section{Auditory stimuli.}

Figure 1 shows the mean pupil sizes over all Ss $(N=29)$ on the seven tone levels. An analysis of variance comparing these seven means showed significance $(F=18.69, \mathrm{df}=6 / 168, \mathrm{p}<.001)$. Duncan's test showed mean number four $(94.2 \mathrm{~dB})$ to be the only mean significantly different $(p<.05)$ from all other means. By the same standard, there is a significant drop from the first tone level to the next higher tone level, and the difference between the second and third tone levels is not significant. In the descending series

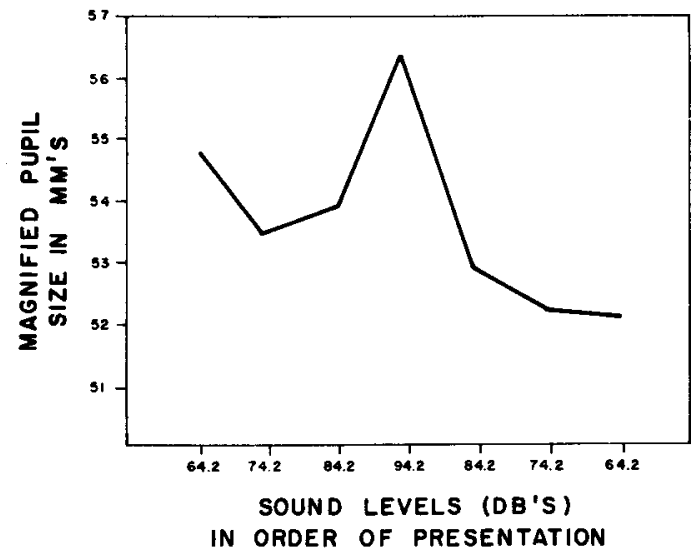

Fig. 1. Pupil size in relation to sound levels. 


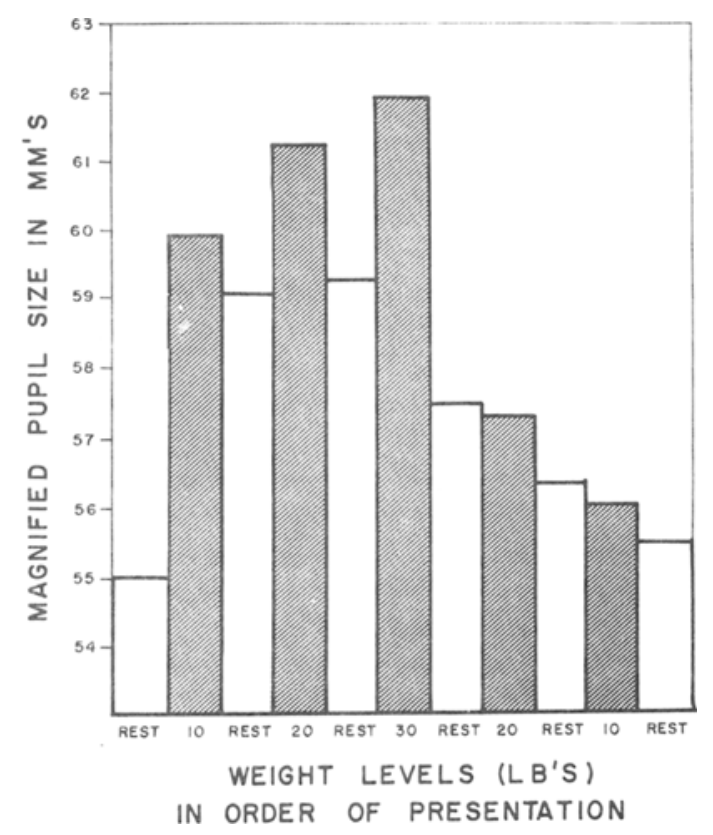

Fig. 2. Pupil size in relation to levels of muscle strain.

of tones, none of the differences is significant among the three tone levels below $94.2 \mathrm{~dB}$, but all of the former are significantly different $(p<.05)$ from the latter.

\section{Muscle Strain.}

Each $S$ received $10-\mathrm{sec}$. rest periods interspersed between $10-\mathrm{sec}$. periods in which he lifted various weights. Figure 2 shows the mean pupil sizes $(\mathrm{N}=30)$ for the various $10-\mathrm{sec}$. periods in the order of their occurrence. In the ascending series of weights, average pupil size is larger during the lifting period for each weight than during the prior rest period. In the descending series, pupil size during lifting periods is larger than during each subsequent rest period. There also is a regular increase first, then decrease, in average pupil size during the ascending and descending series for the rest periods.

\section{Threat of Gunshot.}

In this task $S$ anticipated the firing of a gun when the number 3 was on the screen before him. Two identical sets of numbers were presented to each $S$ in the following order: $1,2,3,4$, and 5 . Since the gun was never actually fired on the number 3 , the appearance of the numbers 4 and 5 probably signalled "relief" for Ss. Figure 3 shows the mean pupil size $(\mathrm{N}=30)$ on the various $10-\mathrm{sec}$. periods. The notation C stands for control slides interspersed among the test slides. The results are self-explanatory.

\section{DISCUSSION}

The data relating to lifted weights make it quite clear that pupil size increases with muscle tension and that the size is directly related to the degree of tension. The relationship between muscle tension and pupil size was further supported in a pilot study (unpublished) performed in preparation for the present experiment. Eight male Ss performed isometric exercises (e.g., fist clenching) while viewing a target asterisk on an otherwise blank screen. Pupil size during each exercise was larger than during a prior rest period, and pupil size was directly related to the rated strenuousness of the exercises. The regularity of the relationship between muscle tension and pupil size leads to the hypothesis that muscle tension may be a mediating link in pupillary response to other forms of activation, which may have been the case, for example, in the effects obtained in this experiment with respect to loud tones and threat of a gunshot.

In the task concerning sound levels, it is clear that pupil size is larger for the loudest sound than for any of the less loud sounds, but no clear-cut pattern of relationship appears among the other sound levels. It may be that marked dilation occurs only when the sound is painfully loud (thereby inducing muscle tension), which may be the case with the loudest sound that was employed (94.2 dB) but which may not be the case with the other sound levels that were employed. It is to be noted, however, that, with the exception of the initial drop from the first sound level to the next higher one (which may have been due to habituation), all of the other mean pupil sizes conform to a simple rule.

The results with respect to threat of a gunshot clearly indicate that fear of that type is directly related to pupil size. Somewhat similar findings are reported by Loewenfeld (1958). The effect is shown in both threat series and in both the ascending anticipa-

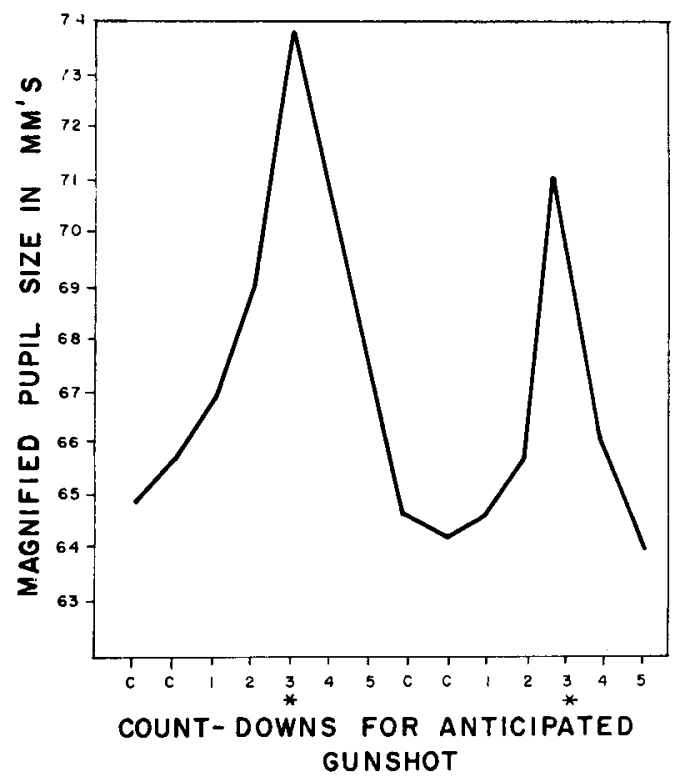

Fig. 3. Fig. Effects on pupil size of threat of a gunshot. 
tory phases and in the subsequent "relief" phases. Changes in pupil size in this task were larger than in any other task, and considerably larger than in all tasks except that involving muscle strain.

The results with respect to novel pictures are only partially conclusive. The combined scores from both novel pictures were significantly larger than the combined scores from the non-novel counterparts, but, considering the pairs separately, the difference is statistically significant for only one pair.

The results from the affect-related pictures indicated that (a) pupil size was larger for the pictures of a pretty girl than for control slides, (b) pupil size was larger when portions of the girl's clothing were removed than when she was fully clothed, and (c) on the other affect-related pictures, pupil size for positive pictures was significantly larger than for neutral or negative pictures, but the difference between the latter two was not significant. For two types of reasons, however, these results should be considered only as suggestive regarding effects on pupil size of the affective qualities of stimuli. First, the pictures differed in complexity and novelty as well as in affective qualities, e.g., in the comparison of responses to a picture of a pretty smiling girl and the picture of a middle-aged woman with a large cancerous growth on her face. Second, it is very difficult to employ complex visual displays in studies of pupillary response without encountering artifactual effects due to different overall luminance of displays, different dispersions of luminance, and different degrees to which the displays induce convergence and/or eye movements. The potential effects of such artifacts have been documented by Loewenfeld (1966) and by Woodmansee (1966). In this experiment, only two of the five sets of stimuli concerned responses to visual displays. One of these two sets consisted of the novel and non-novel pictures, and the other set consisted of all affect-related pictures, including pictures of the semi-nude female. With novel pictures, visual artifacts were minimized by dealing with simple line drawings set against homogeneous gray fields.

Readings from the spotphotometer (Table 1) make it doubtful that the differences in pupil size among affect-related pictures were due entirely to visual artifacts. In the comparison of the semi-nude girl with control slides, the control slides actually were slightly darker, which would have worked against finding the results which were obtained. In the comparisons of pleasant, unpleasant, and neutral pictures with one another, mean differences in luminance and differences in dispersion of luminance were tiny in comparison to the differences in luminance required to obtain noticeable differences in pupil size (Bartley, 1951, pp. 980-981).

The experiment attempted only to survey the gross effects on pupillary response of five types of stimulation, which it may be heuristically useful to think of as sharing to some extent in a common process of activation. Sokolov (1963) reports results with treatments similar in some cases to those reported here but mainly employing dependent measures concerning autonomic functioning and brain waves rather than pupillary response.

There are numerous possible extensions and improvements of methods of investigating effects on pupillary response of each of the forms of stimulation separately. Extensions and improvements for the study of effects of muscle strain and loud tones on pupil size are (a) the use of numerous random orders of presenting stimuli of different magnitudes or the use of a Latin Square design in which each subject is presented all stimuli in all possible orders, and (b) the employment of relatively long (e.g., 1 min.) rest intervals between stimuli to reduce cumulative effects of fatigue, habituation, boredom, and others. There are numerous examples of cumulative effects in this study, e.g., (a) smaller pupil sizes in the second threat series than in the first series, (b) a significant drop in pupil size from the first tone in the series to two louder tones that followed, (c) a significant difference in the first comparison of a novel stimulus with a non-novel stimulus but no significant difference in the second such comparison, and (d) larger pupil sizes in an ascending series of lifted weights than in the descending series.

To answer questions regarding effects of novelty on pupil size, it would be important to employ a larger number and wider variety of novel stimuli than were feasible to employ in this experiment. Also, unlike the practice in this study of displaying the non-novel stimuli before the novel stimuli, it would be important to either randomly vary order over subjects or systematically counter-balance orders of presentation.

The use of complex visual displays to investigate the effects of affective tone on pupil size will probably continue to be beset by difficult technical problems. One solution, of course, is to investigate affective tone with non-visual stimuli, e.g., recorded messages relating to violence, sex, and other themes. If visual displays are used, the complexity of the display can be greatly reduced by dealing with words relating to pleasant and unpleasant objects and events rather than dealing with the objects and events themselves. One attempt to find differences in pupil size relating to differences in the affective properties of words, however, met with negative results (Paivio \& Simpson, 1966). One way to avoid visual artifacts in studies of the effects of affect-related stimuli on pupil size is to work with simple stimuli that have been positively or negatively conditioned, e.g., nonsense syllables that have been associated with electric shock or with the winning of money. By counterbalancing the roles of the syllables in different groups of Ss, visual artifacts would be entirely eliminated as systematic factors. If one works with complex visual stimuli 
(e.g., pictures of people in different settings), it is necessary to (a) reduce mean differences in luminance and dispersions of luminance as much as possible, and (b) employ numerous different visual displays to represent different types of affect.

\section{References}

Bartley, S. H. The psychophysiology of vision. In S. S. Stevens (Ed.), Handbook of experimental psychology. New York: John Wiley \& Sons, 1951. Pp. 980-981.

Berlyne, D. E. Curiosity and exploration. Science, 1966, 153, 25-33.

Hess, E. H. Attitude and pupil size. Scient. American, 1965, 212 , 46-54.

Loewenfeld, I. E. Mechanisms of reflex dilation of the pupil. Historical review and experimental analysis. Documenta Ophthalmol., 1958, 12, 185-448.

Loewenfeld, I. E. Comment on Hess' findings. Surt. Ophthalmol. in press.
Lowenstein, 0. Experimentelle beitrage zur lehre von den katatonischen pupillenveranderungen. Mschr. Psychiat. Neurol., $1920,47,194-215$.

Paivio, A., \& Simpson, H. The effect of word abstractness and pleasantness on pupil size during an imagery task. Psychon. Sci., 1966, 5, 55-56.

Sokolov, E. N. Perception and the conditioned reflex. New York: Macmillan, 1963.

Woodmansee, J. J. An evaluation of the pupil response as a measure of attitude toward Negroes. Unpublished doctoral dissertation, University of Colorado, 1965.

Woodmansee, J. J. Methodological problems in pupillographic experiments. Paper presented at APA, 1966.

\section{Nofes}

1. This study was supported in part by a research grant from the Vocational Rehabilitation Administration, No. RD-1479. Appreciation is expressed to Dr. E. H. Hess and J. M. Polt for numerous forms of help and advice in this experiment.

2. Now in the Department of Psychology at Florida State University.

(Accepted for publication January 16, 1967.) 